\title{
Screening of volatile composition from Portuguese multifloral honeys using headspace solid-phase microextraction-gas chromatography-quadrupole mass spectrometry
}

\author{
M. Pontes, J.C. Marques, J.S. Câmara* \\ Centro de Química da Madeira, Departamento de Química da Universidade da Madeira, \\ Campus Universitário da Penteada, 9000-390 Funchal, Portugal \\ Received 15 March 2007; received in revised form 14 May 2007; accepted 18 May 2007 \\ Available online 26 May 2007
}

\begin{abstract}
The volatile composition from four types of multifloral Portuguese (produced in Madeira Island) honeys was investigated by a suitable analytical procedure based on dynamic headspace solid-phase microextraction (HS-SPME) followed by thermal desorption gas chromatography-quadrupole mass spectrometry detection (GC-qMS). The performance of five commercially available SPME fibres: $100 \mu \mathrm{m}$ polydimethylsiloxane, PDMS; $85 \mu \mathrm{m}$ polyacrylate, PA; 50/30 $\mu \mathrm{m}$ divinylbenzene/carboxen on polydimethylsiloxane, DVB/CAR/PDMS (StableFlex); $75 \mu \mathrm{m}$ carboxen/polydimethylsiloxane, CAR/PDMS, and $65 \mu \mathrm{m}$ carbowax/divinylbenzene, CW/DVB; were evaluated and compared. The highest amounts of extract, in terms of the maximum signal obtained for the total volatile composition, were obtained with a DVB/CAR/PDMS coating fibre at $60{ }^{\circ} \mathrm{C}$ during an extraction time of $40 \mathrm{~min}$ with a constant stirring at $750 \mathrm{rpm}$, after saturating the sample with $\mathrm{NaCl}(30 \%)$. Using this methodology more than one hundred volatile compounds, belonging to different biosynthetic pathways were identified, including monoterpenols, $\mathrm{C}_{13}$-norisoprenoids, sesquiterpenes, higher alcohols, ethyl esters and fatty acids. The main components of the HS-SPME samples of honey were in average ethanol, hotrienol, benzeneacetaldehyde, furfural, trans-linalool oxide and 1,3-dihydroxy-2-propanone.
\end{abstract}

(C) 2007 Elsevier B.V. All rights reserved.

Keywords: Honey; Volatile compounds; Solid-phase microextraction; GC-qMS

\section{Introduction}

Honey is a natural product produced by Apis mellifera bees from the nectar of plants and has for long been an excellent nutritional option for many generations due to its health benefits (one of the traditional sources for treatment of flue and common cold in the region) [1], has been reported to be effective in gastrointestinal disorders, in healing of wounds and burns, as an anti-microbial agent [2]. The healing effect of honey is due to the enzyme glucose oxidase, this enzyme is virtually inactive in full-density honey but becomes active in diluted honey producing hydrogen peroxide and gluconic acid from glucose. In addition, many natural antibacterial compounds have been identified from different types of honey [2]. Honey, as a source of antioxidants has been proven to be effective against deterioative

\footnotetext{
* Corresponding author. Tel.: +351 291705112; fax: +351 291705149 .

E-mail address: jsc@uma.pt (J.S. Câmara).
}

oxidation reaction in food [3]. The antibacterial activity of honey is attributed both to physical factors, acidity and osmolarity and chemical factors, hydrogen peroxide, volatiles, beeswax, nectar, pollen and propolis $[2,3]$.

Honey includes over 400 different chemical compounds, more than $95 \%$ mainly formed by sugars and water, whereas proteins, vitamins (mainly vitamin B6, thiamin, niacin, riboflavin, and pantothenic acid), essential minerals (including calcium, copper, iron, magnesium, manganese, phosphorus, potassium, sodium, and zinc), pigments, flavours, free amino acids and volatile compounds constitute minor components [4]. The sugars present in honey are mainly fructose (about 38.5\%) and glucose (about $31.0 \%$ ). The remaining carbohydrates include maltose, sucrose, and other complex carbohydrates.

The chemical composition of honey is highly dependent to the nectar source and the botanical origin of the nectar foraged by bees [1]. Aroma compounds are present in honey at very low concentrations as complex mixtures of volatile components of different chemical families belonging, in general, to 
monoterpenes, $\mathrm{C}_{13}$-norisoprenoids, sesquiterpenoids, benzene derivatives [5] and in lowest content, higher alcohols, esters, fatty acids, ketones, terpenes and aldehydes. Some of these substances are present in honey collected by bees, and have been described as characteristics of the floral source (could be related to plant characteristics), and other compounds, like some alcohols, branched aldehydes, and furfural derivatives, may be related to the microbial purity of processing and storage conditions of honey [6]. The quantitative analysis of volatile compounds present in such samples is extremely demanding due: (1) to complex chemical composition of the volatile fraction and (2) the fact of individual volatile compounds can be present in a wide range of concentration. Honey volatile fractions have been used as quality markers for the authenticity of the floral origin [7,8]. It also prevents overpayment and helps to identify frauds [7].

Traditional analytical methods employing organic solvents such as liquid-liquid extraction [9], simultaneous distillation-extraction (SDE) [10], supercritical fluid extraction (SFE) [11], solid-phase extraction (SPE) [12] and ultrasound extraction [13] were commonly used. These are hazardous since requires large amounts of toxic and expensive solvents, are labour-intensive and time-consuming and requires the preconcentration of the extract. Each procedure of the sample preparation is subject to inconveniences, but offers specific advantages under determined circumstances. Nowadays, alternative to these classical methods that may overcome their disadvantages, more easier and selective, are used such as solidphase microextraction (SPME), developed by Pawliszyn and coworker $[14,15]$ in the early 1990 s and more recently stir bar sorptive extraction (SBSE) developed in the late 1990s by Baltussen et al. [16]. This technique uses a TwisterTM, a glass stir bar onto which is bonded a sorptive phase, often polydimethylsiloxane (PDMS), in quantities far in excess of those found on SPME fibres [17]. SPME is an equilibrium technique that requires a previous optimisation of the extraction parameters that can affect extraction efficiencies, in order to obtain high recoveries of volatiles. SPME sampling can be performed in three basic modes: direct extraction (the analytes were transported directly from matrix to the extracting phase), headspace extraction (the analytes are extracted from the gas phase equilibrated with the sample) and extraction with membrane protection (the fibre is separated from the sample with a selective membrane). The selection of the sampling mode is dependent of the nature of the compounds to be analysed and the sample type. Bearing in mind that one of the goals of this study was to screen volatile compounds from honeys, the headspace sampling mode was the most appropriate. The headspace SPME process protects the fibre from adverse effects caused by non-volatile compounds present in the sample matrix namely sugars, and allows modifications, as for example: $\mathrm{pH}$, with no effect in the fibre. Moreover, the equilibration times for volatile compounds are shorter for headspace SPME extraction than for direct extraction under the same conditions.

Since the first SPME fibres becomes commercially available, it has been more and more used and the fields of application have been continuously growing, including a wide range of food analysis, namely the volatile composition of wines [18-22], beers [23], whiskeys [24-26], several kinds of fruits [27-31] and honeys [32-36], with nowadays about 3000 research papers published. The technique gained growing acceptance and increasing use in routine laboratories and industrial applications. This method shows clear advantages compared with traditional techniques, eliminates the use of (toxic) organic solvents, allows the quantification of a large number of molecules, no or little manipulation/preparation of samples, substantially shortness the time of analysis and moreover are simple and faster techniques, and covers a wide range of sampling techniques, including field, in situ and air sampling. Generally accepted disadvantages are relatively lotto-lot variations, sensitivity against organic solvents and the limited range of stationary phases which are commercially available.

In this study, headspace SPME combined with GC-qMS, was developed and applied to evaluating the volatile composition profile of different multifloral honey samples (H1-H4). A preliminary screening of fibre of various polarities was carried out in order to select the best coating for the matrix. Comparison between the performance of the five sorbent materials is given. To confirm the applicability of the SPME, comparative study on the characteristic GC-qMS volatile honey profiles were performed. The possibility of differentiation from the investigated honeys was evaluated.

\section{Experimental}

\subsection{Chemicals and materials}

All reagents used were analytical quality and all solvents were HPLC grade. Sodium chloride $(99.5 \%)$ used to obtain the adequate ionic strength (decrease the solubility of the aroma molecules which then partition more readily into the headspace improving the adsorption of analytes in SPME analysis), was supplied by Merck (Darmstadt, Germany). Water was purified through a Milli-Q purification system (Millipore). The $\mathrm{C}_{8}-\mathrm{C}_{20} n$-alkanes series, and the chemical standard used as internal standard, 3-octanol, were supplied by Sigma-Aldrich (Spain).

The SPME fibres tested and compared in this work, polydimethylsiloxane layer (PDMS, $100 \mu \mathrm{m})$, recommended for nonpolar volatiles; polyacrylate (PA, $85 \mu \mathrm{m}$ ) with high selectivity for polar semivolatile compounds; divinylbenzene-carboxen-polydimethylsiloxane (DVB/CAR/PDMS, 50/30 $\mu \mathrm{m}$ ) on a $1 \mathrm{~cm}$ StableFlex fibre, recommended for flavours (volatiles and semivolatiles); carboxen-polydimethylsiloxane (CAR/PDMS, $75 \mu \mathrm{m}$ ); carbowax-divinylbenzene (CW/DVB, $65 \mu \mathrm{m})$ and the SPME holder for manual sampling, were obtained from Supelco (Bellefonte, PA, USA). The coating of all fibres was $1 \mathrm{~cm}$ long. The fibres were conditioned prior to use according to the manufacturer's instructions by inserting them into the GC injector port. Before the first daily analysis the fibres were conditioned for $20 \mathrm{~min}$. A blank test was performed to check possible carry-over. 


\subsection{Honey samples}

This study was carried out on 16 multifloral honeys, H1-H4 (four samples from each honey) from four different regions of Madeira Island (Portugal) where predominates the wild flora, eucalyptus, hissed and rosemary. All samples were obtained from local stores and were processed using the traditional procedures. None of these samples underwent any treatment that could alter their composition.

All samples were contained in glass bottles and stored at $4{ }^{\circ} \mathrm{C}$ until analysis. All analysis, were carried out four times.

\subsection{SPME methodology}

In order to select the best fibre for honey volatile composition, five SPME coatings of different polarity and extraction mechanisms were tested. The methodology developed and optimised by Câmara et al. [37] for the volatile compounds extraction using manual SPME was used in this study with minor modifications. The H1 honey sample was selected as the matrix for comparison of the performance of the fibres. The fibre that presented the most complete profile of $\mathrm{H} 1$ honey volatile compounds was chosen for the study. The extraction was carried out at $60^{\circ} \mathrm{C}$ (controlled temperature) and each measurement was repeated four times.

For each extraction $15 \mathrm{~g}$ of sample was diluted 1:1 with deionised water (Milli-Q). The dilution decrease the density of the matrix making easy the evaporation of analytes of the interest otherwise retained for sugars. For headspace sampling, $30 \mathrm{~mL}$ of the sample was immediately placed in a $60 \mathrm{~mL}$ ambar glass vial (volume ratio headspace/solution was 1:1) hermetically sealed and spiked with 3-octanol $\left(250 \mu \mathrm{L}\right.$ at $\left.422 \mathrm{mg} \mathrm{L}^{-1}\right)$ and 4-methyl2-pentanol $\left(125 \mu \mathrm{L}\right.$ at $\left.422 \mathrm{mg} \mathrm{L}^{-1}\right)$ (Sigma-Aldrich) used as internal standards, and equilibrated during $40 \mathrm{~min}$ in a thermostatic bath on a stirrer. The extractions were carried out without adjust of $\mathrm{pH}$. The ionic strength was increased using $\mathrm{NaCl}$ (30\%, $\mathrm{w} / \mathrm{v}$ ) to improve the extraction efficiency by decreasing the solubility of hydrophilic compounds in the aqueous phase. The SPME fibre was then exposed to the headspace of the sample and kept for $40 \mathrm{~min}$ at $60^{\circ} \mathrm{C}$. As stirring usually improves the extraction, because the static layer resistant to mass transfer is destroyed (facilitate mass transport between the bulk of the aqueous sample and the fibre), all the experiments were performed under constant stirring velocity (750 rpm).

After sampling, the SPME fibre was withdrawn into the needle, removed from the vial and inserted into the hot injector port $\left(260^{\circ} \mathrm{C}\right)$ of the GC-qMS system for 6 min where the extracted analytes were thermally desorbed and transferred directly to the analytical column.

\subsection{Gas chromatography-quadrupole mass spectrometry detection $(G C-q M S)$}

The volatile compounds extracted by dynamic headspace SPME procedure from honey, were tentatively identified using an Agilent 6890N (Palo Alto, CA, USA) gas chromatograph system coupled to an Agilent 5975 quadrupole inert mass selective detector equipped with a $30 \mathrm{~m} \times 0.25 \mathrm{~mm}$ i.d., with a $0.25 \mu \mathrm{m}$ film thickness, BP-20 fused silica capillary column, according to the method described by Câmara et al. [37]. Helium (Helium N60, Air Liquid, Portugal) was used as the carrier gas at a flow rate $\approx 1 \mathrm{~mL} \mathrm{~min}^{-1}$ (column-head pressure: $13 \mathrm{psi}$ ). An insert of $0.75 \mathrm{~mm}$ i.d. was used and the injector temperature was fixed at $260{ }^{\circ} \mathrm{C}$. Splitless injections were used. The temperature used included the following settings: initial temperature of $50^{\circ} \mathrm{C}$ was held for $1 \mathrm{~min}$ and then increased in three steps: $50-100^{\circ} \mathrm{C}$, at $2.5^{\circ} \mathrm{C} \mathrm{min}-1 ; 100-180{ }^{\circ} \mathrm{C}$, at $2^{\circ} \mathrm{C} \mathrm{min}^{-1}$ and $180-220^{\circ} \mathrm{C}$, at $15^{\circ} \mathrm{C} \mathrm{min}^{-1}$. Each step was preceded by a small period at constant temperature for 2,1 and $10 \mathrm{~min}$, respectively. The manifold, GC-qMS interface and quadrupole temperatures were held at 180,220 and $180^{\circ} \mathrm{C}$, respectively. The detection was performed by a 5975 mass spectrometer in the electronic impact (EI) mode (ionization energy, $70 \mathrm{eV}$; source temperature, $180^{\circ} \mathrm{C}$ ). The electron multiplier was set to the auto tune procedure. The mass acquisition range, made in full scan mode, was $30-300 \mathrm{~m} / z$; $1.9 \mathrm{spectra} / \mathrm{s}$.

Compounds were identified by comparing the MS fragmentation pattern with those of the pure standards and mass spectrum of the unknown peaks with those stored in the NIST GC/MS library, retention time of the pure standards obtained under the same conditions, and Kováts retention indices (RI). For the determination of the RI a $\mathrm{C}_{8}-\mathrm{C}_{20} n$-alkanes series was used. The relative amounts of individual components are expressed as percent peak areas (RPA, \%) relative to the total peak area.

\subsection{Statistical analysis}

Significant differences among the honey samples were determined by one-way analysis of variance (ANOVA) using a SPSS Program, Version 14.0 (SPSS Inc., 2006). Principal component analysis (PCA) and stepwise linear discriminant analysis (SLDA) were performed using the same SPSS program. These techniques were applied to the normalized total peak areas from different chemical classes.

\section{Results and discussion}

Sixteen honey samples from different multifloral origins were analysed with the objective to identify and compare their volatile compounds profiles. Differences in the total ion current (TIC) chromatographic profiles were observed when comparing the studied honeys. TIC chromatograms from $\mathrm{H} 1-\mathrm{H} 4$ samples were compared in terms of total areas of the volatile compounds and number of compounds. The identified compounds were organized in different groups according to their chemical structure. This was done for $\mathrm{C}_{13}$ norisoprenoids/monoterpenes, sesquiterpenoids, higher alcohols, fatty acids, ethyl esters, furanic compounds, carbonyl compounds, aliphatic and aromatic hydrocarbons, while compounds of different structures were considered together as the class "miscellaneous".

From these identification we found that carbonyl compounds, furanic compounds, higher alcohols and $\mathrm{C}_{13}$ - 
norisoprenoids/monoterpenes, constitute a main part of flavour studied honeys, and they probably play a significant role in their flowery notes. These founds are in good agreement with previous reports [34,35]. As predominant compounds trans-linalool oxide, furfural, hotrienol and in minor extent, 1,3-dihydroxy2-propanone, 5-hydroxymethylfurfural, benzeneacetaldehyde, ethyl decanoate, ethyl dodecanoate, $o$-methoxyacetophenone and 2-ethyl hexanoic acid were found. The two fatty acid ethyl esters may contribute with sweety and fruity notes while benzeneacetaldehyde may contribute with flowery, rose and honey notes.

Furanic compounds such as furfural, 1-(2-furanyl)-ethanone and 5-hydroxymethylfurfural were presented in all samples. Several aliphatic and aromatic hydrocarbons arise from bee wax which has not been completely separated during harvest and processing, were identified.

\subsection{Selection of SPME fibre coating}

The fibre coating used influences the chemical nature of the extracted analyte that is established by their characteristic polarity and volatility. To evaluate the extraction yields of the honey volatile components by HS-SPME, and taking account of the physico/chemical characteristics of the targets under consideration, we tested five types of fibre (CAR/DVB, CW/PDMS, PDMS, PA, and DVB/CAR/PDMS) among those used most routinely for assaying volatiles. A few key experimental factors which influence the HS-SPME extraction yield, namely time required for the target analytes to reach equilibrium and extraction temperature, were previously evaluated by Câmara et al. [37], and applied in this work. Bearing in mind the obtained results, each fibre was exposed to the headspace at the same temperature $\left(60^{\circ} \mathrm{C}\right)$ during the same extraction time (40 min). For reasons of comparability all tests were carried out with the same honey sample (H1). The comparison of the SPME fibre performance was made in terms of extraction efficiency, number of identifiable compounds in the extract and reproducibility. The chromatographic profiles presented in Fig. 1, obtained for a H1 honey sample by using different coatings in same experimental conditions, shows the different extraction efficiency of the fibres. The results obtained using the five fibres on the same H1 sample, in rigorously reproduced temperature and exposure time conditions, are reported in Table 1 . The qualitative composition of honey volatiles and the number of identified compounds using the five fibres under study is very different. As can be seen in Table 1 with DVB/CAR/PDMS fibre a total of 46 compounds were identified whilst with the PA, CW/DVB, CAR/PDMS and PDMS coatings, were detected only, 32, 30, 35 and 17 compounds, respectively. The semi-polar DVB/CAR/PDMS fibre allowed the best efficiency of extraction for volatile compounds while under the same conditions PDMS fibre had the lowest sorption capacity. The former fibre provided the best sensitivity in terms of total compound peak areas, highest number of detected compounds and high reproducibility, hence this fibre was chosen for evaluation of volatile compounds in honeys (Table 2 ). PA fibre coating extracted
$71.8 \%$ of DVB/CAR/PDMS while PDMS coating extracted the lowest amount (about $32.0 \%$ of DVB/CAR/PDMS). Similar amounts of volatiles (57.4-60.2\% of DVB/CAR/PDMS) were extracted when using either, CW/DVB or CAR/PDMS coatings (Table 2). From Fig. 2, it can be observed that the fibres show different selectivity to different target compounds.

Higher alcohols (HA) have a larger affinity for PA fibre. This coating also present better sensitivity for furanic compounds (FC), carbonyl compounds $(\mathrm{CaC})$ and miscellaneous. DVB/CAR/PDMS coating showed a strong extraction capacity for aliphatic and aromatic hydrocarbons (HSHAr), $\mathrm{C}_{13}$ norisoprenoids/monoterpenes (NT), sesquiterpenoids (S) and ethyl esters (EEs).

Some characteristic honey compounds were isolated by the five fibres, such as toluene, trans-linalool oxide, furfural, linalool, hotrienol, benzeneacetaldehyde, 1,3-dihydroxy2-propanone, 2,3-dihydro-3,5-dihydroxy-6-methyl-4H-pyran4one (DDMP) and 5-hydroxymethylfurfural.

\subsection{Volatile compounds in honey samples}

The proposed HS-SPME method, previously optimised and validated, was applied to determine the content of volatile patterns in four commercial available Portuguese honeys. Each honey was analysed four times using the best sampling conditions described above. A characteristic GC-qMS profile of each honey obtained with DVB/CAR/PDMS using the experimental conditions discussed above is shown in Fig. 3. More than 100 volatile compounds belonging to several chemical classes were positively identified, including monoterpenes, $\mathrm{C}_{13}$-norisoprenoids, sesquiterpenoids, higher alcohols, fatty acids ethyl esters, fatty acids, furanic compounds, carbonyl compounds and aliphatic/aromatic hydrocarbons. Most of the volatile compounds were identified by a library search NIST. In some cases a comparison with authentic compounds was performed. The Kováts retention indices were calculated for each peak and compared with the literature in order to ensure the correct identification of the compounds. Table 3 summarises the average $(n=4)$ relative composition determined in the mutifloral studied honeys. The relative composition of every flavour compound was calculated as the percent ratio of the respective peak area relative to the total peak area (RPA, \%) and relative to the compound with highest peak area in each honey (RPC, \%).

A total of 110 volatile compounds were identified in investigated honey samples. Fifteen of these volatiles: ethanol, toluene, 1-methyl-2-(1-methylethyl)-benzene, translinalool oxide, acetic acid, furfural, 1-(2-furanyl)-ethanone, linalool, hotrienol, benzeneacetaldehyde, 1-nonanol, 1,3dihydroxy-2-propanone, nonanoic acid, DDMP and 5hydroxymethylfurfural, were detected in all samples (Table 3) but the ratio between the single components were different for each honey. Some of these 15 compounds ethanol, toluene, trans-linalool oxide, furfural, hotrienol and benzeneacetaldehyde, have been reported as common components of various honeys [32-36]. 


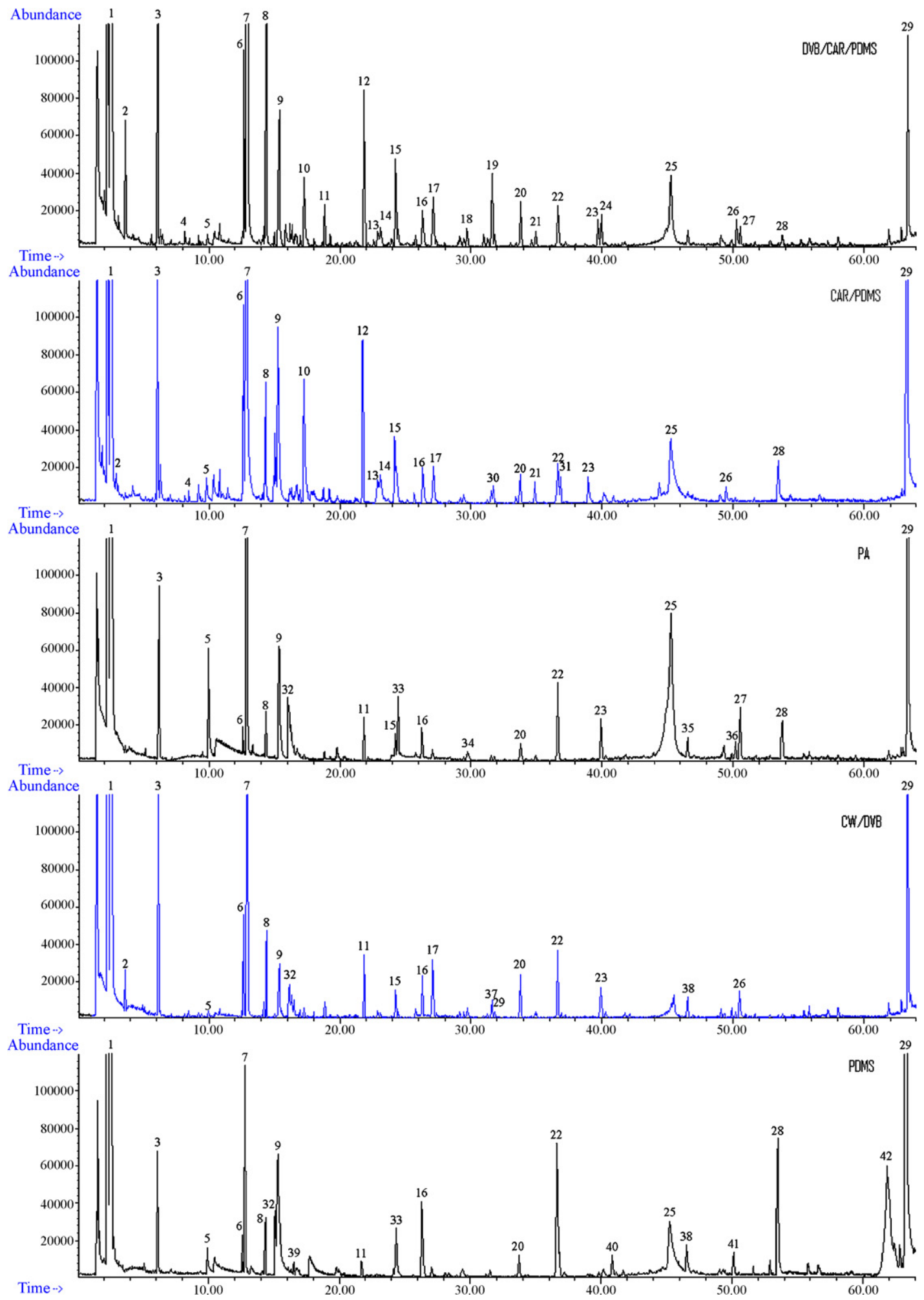

Fig. 1. Chromatograms obtained by SPME analysis of $\mathrm{H} 1$ honey with different fibres using in the headspace sampling mode with $30 \% \mathrm{NaCl}$ and at $60{ }^{\circ} \mathrm{C}$ during 40 min. Peak identification: (1) ethanol; (2) toluene; (3) 4-methyl-2-pentanol (IS); (4) 1,3-butanediol; (5) 1-hydroxy-2-propanone; (6) nonanal; (7) 3-octanol (IS); (8) trans-linalool oxide; (9) furfural; (10) benzaldehyde; (11) linalool; (12) hotrienol; (13) benzeneacetaldehyde; (14) acetophenone; (15) 1-nonanol; (16) eicosane; (17) naphthalene; (18) 3-ethyl-2-pentene; (19) 2-methyl-2-phenylethyl ester propanoic acid; (20) E-6,10-dimethyl-5,9-undecadien-2-one; (21) $\alpha$-2-propenylbenzenemethanol; (22) heptadecane; (23) 2-ethyl-hexanoic acid; (24) 1-ethyl-2-hepthyl-cyclopropane; (25) 1,3-dihydroxy-2-propanone; (26) nonanoic acid; (27) $N$-(4-hydroxyphenyl)acetamide; (28) 2,3-dihydro-3,5-dihydroxy-6-methyl-4H-pyran-4one; (29) 5-hydroxymethylfurfural; (30) $\alpha$-methyl benzenemethanol; (31) $\alpha$ ionol; (32) acid acetic; (33) furanmethanol; (34) 2-hydroxy-2-cyclopenten-1-one; (35) tridecane; (36) acetoxymethyl-2-furaldehyde; (37) ethyl ester benzenepropanoic acid; (38) nonadecane; (39) hexadecane; (40) furyl hydroxymethyl ketone; (41) 5-acetoxymethylfurfural; (42) 4-(2-hydroxyethyl)phenol. 
Table 1

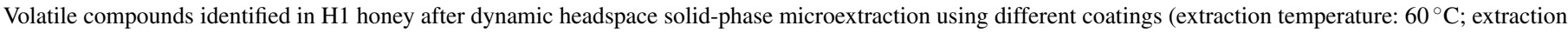
time: $40 \mathrm{~min}$ )

\begin{tabular}{|c|c|c|c|c|c|c|c|c|}
\hline \multirow[t]{2}{*}{$\mathrm{RT}(\min )$} & \multirow[t]{2}{*}{$\mathrm{KI}^{\mathrm{a}}$} & \multirow[t]{2}{*}{ Compound } & \multirow[t]{2}{*}{ Identity $^{\mathrm{b}}$} & \multicolumn{5}{|c|}{ SPME coating } \\
\hline & & & & PA & CW/DVB & CAR/PDMS & PDMS & DVB/CAR/PDMS \\
\hline 2.575 & 929 & Ethanol & A, B & $\mathrm{x}$ & $\mathrm{x}$ & $\mathrm{x}$ & $\mathrm{x}$ & $\mathrm{x}$ \\
\hline 3.614 & 1023 & Toluene & A, B & & $\mathrm{x}$ & & & $\mathrm{x}$ \\
\hline 4.186 & 1064 & Hexanal & $\mathrm{A}, \mathrm{B}$ & & & $\mathrm{X}$ & & \\
\hline 6.295 & 1178 & Heptanal & A, B & & & $\mathrm{x}$ & & $\mathrm{x}$ \\
\hline 8.259 & 1254 & 1,3-Butanediol & A & & & & & $\mathrm{x}$ \\
\hline 8.481 & 1261 & 1-Methyl-3-(1-methylethyl)-benzene & A, B & $\mathrm{x}$ & & $\mathrm{x}$ & & $\mathrm{x}$ \\
\hline 9.233 & 1285 & 2,4,6,8-Tetramethyl-1-undecane & $\mathrm{B}$ & $\mathrm{x}$ & & $\mathrm{x}$ & & \\
\hline 9.942 & 1307 & 1-Hydroxy-2-propane & B & $\mathrm{x}$ & & $\mathrm{x}$ & $\mathrm{x}$ & $\mathrm{x}$ \\
\hline 10.864 & 1337 & Linalool & $\mathrm{B}$ & $\mathrm{x}$ & & $\mathrm{x}$ & & \\
\hline 12.668 & 1389 & Nonanal & A, B & $\mathrm{x}$ & $\mathrm{x}$ & $\mathrm{x}$ & & $\mathrm{x}$ \\
\hline 12.796 & 1392 & (E)-2-Nonen-1-ol & $\mathrm{A}, \mathrm{B}$ & & & & $\mathrm{x}$ & $\mathrm{x}$ \\
\hline 14.130 & 1432 & Heptanoic acid ethyl ester & B & $\mathrm{x}$ & & $\mathrm{x}$ & & $\mathrm{x}$ \\
\hline 14.274 & 1436 & 1,4-Diclorobenzene & $\mathrm{A}, \mathrm{B}$ & $\mathrm{x}$ & $\mathrm{x}$ & $\mathrm{x}$ & & $\mathrm{x}$ \\
\hline 14.401 & 1439 & Trans-linalool oxide & $\mathrm{B}$ & $\mathrm{x}$ & $\mathrm{x}$ & $\mathrm{x}$ & $\mathrm{x}$ & $\mathrm{x}$ \\
\hline 15.025 & 1457 & Acetic acid & B & & $\mathrm{x}$ & & $\mathrm{x}$ & $\mathrm{x}$ \\
\hline 15.368 & 1466 & Cis-linalool oxide & B & & $\mathrm{x}$ & & & \\
\hline 15.368 & 1466 & Furfural & A, B & $\mathrm{x}$ & & $\mathrm{x}$ & $\mathrm{x}$ & $\mathrm{x}$ \\
\hline 15.767 & 1477 & $\alpha$-Cubebeno & A, B & & & & & $\mathrm{x}$ \\
\hline 16.149 & 1486 & Methyl ester nonanoic acid & A, B & $\mathrm{x}$ & & $\mathrm{x}$ & & \\
\hline 16.578 & 1497 & Hexadecane & B & & $\mathrm{x}$ & & & $\mathrm{x}$ \\
\hline 16.764 & 1502 & 1-(2-Furanyl)-ethanone & A, B & $\mathrm{x}$ & & $\mathrm{X}$ & & $\mathrm{x}$ \\
\hline 17.009 & 1508 & $\mathrm{TBH}^{\mathrm{c}}$ & B & & $\mathrm{x}$ & & & $\mathrm{x}$ \\
\hline 17.009 & 1508 & $(E, E, E)-2,4,6$-Octatriene & A, B & $\mathrm{x}$ & & $\mathrm{x}$ & & \\
\hline 17.300 & 1515 & Benzaldehyde & A, B & & $\mathrm{x}$ & $\mathrm{x}$ & & $\mathrm{x}$ \\
\hline 18.849 & 1549 & $(S)$-Linalool & B & & $\mathrm{x}$ & & & $\mathrm{x}$ \\
\hline 18.849 & 1549 & 5-Methyl-1,3,6-heptatriene & A, B & $\mathrm{x}$ & & $\mathrm{x}$ & & \\
\hline 19.248 & 1558 & 3-Methyl-1,5-pentenediol & $\mathrm{B}$ & & & & & $\mathrm{x}$ \\
\hline 19.248 & 1558 & 1-Hexene & $\mathrm{A}, \mathrm{B}$ & $\mathrm{x}$ & & $\mathrm{x}$ & & \\
\hline 19.801 & 1569 & 5-Methylfurfural & $\mathrm{B}$ & & & & & $\mathrm{x}$ \\
\hline 20.052 & 1574 & $\beta$-Elemene & $\mathrm{B}$ & & $\mathrm{x}$ & & & \\
\hline 21.343 & 1600 & $\alpha$-4-Dimethyl-3-cyclohexene-1-acetaldehyde & $\mathrm{B}$ & & & & & $\mathrm{x}$ \\
\hline 21.840 & 1611 & Hotrienol & B & $\mathrm{x}$ & $\mathrm{x}$ & $\mathrm{x}$ & $\mathrm{x}$ & $\mathrm{x}$ \\
\hline 22.144 & 1617 & Dihydro-cis- $\alpha$-copaene- 8 -ol & $\mathrm{B}$ & & & & & $\mathrm{x}$ \\
\hline 22.589 & 1626 & Pulegone & $\mathrm{B}$ & & & & & $\mathrm{x}$ \\
\hline 22.893 & 1633 & Phenylacetaldehyde & $\mathrm{B}$ & $\mathrm{x}$ & $\mathrm{x}$ & $\mathrm{x}$ & & $\mathrm{x}$ \\
\hline 23.122 & 1637 & Acetophenone & B & $\mathrm{x}$ & $\mathrm{x}$ & $\mathrm{x}$ & & $\mathrm{x}$ \\
\hline 23.475 & 1644 & 3-Carene & A, B & & & & & $\mathrm{x}$ \\
\hline 23.981 & 1654 & 1-Nonanol & $\mathrm{A}, \mathrm{B}$ & $\mathrm{x}$ & $\mathrm{x}$ & $\mathrm{x}$ & & $\mathrm{x}$ \\
\hline 24.252 & 1660 & 2-Furanmethanol & A, B & $\mathrm{x}$ & $\mathrm{x}$ & $\mathrm{x}$ & $\mathrm{x}$ & $\mathrm{x}$ \\
\hline 25.472 & 1683 & D-Germacrene & B & & & & & $\mathrm{x}$ \\
\hline 26.312 & 1698 & Heptadecane & $\mathrm{B}$ & $\mathrm{x}$ & $\mathrm{X}$ & $\mathrm{x}$ & $\mathrm{x}$ & $\mathrm{x}$ \\
\hline 27.090 & 1714 & Naphthalene & A, B & $\mathrm{x}$ & $\mathrm{x}$ & $\mathrm{x}$ & & $\mathrm{x}$ \\
\hline 28.038 & 1733 & $\beta$-Cubebene & $\mathrm{A}, \mathrm{B}$ & & & & & $\mathrm{x}$ \\
\hline 29.198 & 1756 & Methyl ester 2-hidroxy-benzoic acid & $\mathrm{A}, \mathrm{B}$ & & & & & $\mathrm{x}$ \\
\hline 29.368 & 1759 & Cis- $\alpha$-bisabolene & A, B & & & & & $\mathrm{x}$ \\
\hline 29.368 & 1759 & $\alpha$-Ocimene & B & & $\mathrm{x}$ & & & \\
\hline 29.734 & 1766 & (Z)-Heptene & A, B & & & & & $\mathrm{x}$ \\
\hline 31.591 & 1801 & DPEPA $^{d}$ & $\mathrm{~B}$ & & & & & $\mathrm{x}$ \\
\hline 31.591 & 1801 & $\beta$-Damascenone & A, B & & $\mathrm{x}$ & & & \\
\hline 31.591 & 1801 & $\mathrm{TMCHB}^{\mathrm{e}}$ & $\mathrm{B}$ & $\mathrm{x}$ & & $\mathrm{x}$ & & \\
\hline 31.819 & 1805 & $\alpha$-Methyl-benzenemethanol & $\mathrm{A}, \mathrm{B}$ & $\mathrm{x}$ & $\mathrm{x}$ & $\mathrm{x}$ & & $\mathrm{x}$ \\
\hline 33.474 & 1839 & Ethyl ester dodecanoic acid & $\mathrm{B}$ & $\mathrm{x}$ & & $\mathrm{x}$ & & \\
\hline 33.774 & 1845 & (E)-6,10-Dimethyl-5,9-undecadien-2-one & $\mathrm{B}$ & $\mathrm{x}$ & $\mathrm{x}$ & $\mathrm{x}$ & $\mathrm{x}$ & $\mathrm{x}$ \\
\hline 35.010 & 1869 & $\alpha$-2-Propenyl-benzenemethanol & $\mathrm{B}$ & $\mathrm{x}$ & & $\mathrm{x}$ & & $\mathrm{x}$ \\
\hline 36.628 & 1898 & Nonadecane & $\mathrm{B}$ & $\mathrm{x}$ & $\mathrm{x}$ & $\mathrm{x}$ & $\mathrm{x}$ & $\mathrm{x}$ \\
\hline 36.918 & 1904 & $\alpha$-Ionol & A, B & & & & $\mathrm{x}$ & \\
\hline 36.918 & 1904 & DDMMP $^{f}$ & A, B & & & & & $\mathrm{x}$ \\
\hline 40.004 & 1967 & 2-Ethyl-hexanoic acid & A, B & & $\mathrm{x}$ & & & \\
\hline 42.142 & 2008 & 2-Methyl-pentanal & $\mathrm{B}$ & & $\mathrm{x}$ & & & \\
\hline 45.000 & 2068 & 1,3-Dihydroxy-2-propanone & A, B & $\mathrm{x}$ & & $\mathrm{x}$ & $\mathrm{x}$ & $\mathrm{x}$ \\
\hline 46.548 & 2098 & 10-Methyl eicosane & B & & $\mathrm{x}$ & & & $\mathrm{x}$ \\
\hline
\end{tabular}


Table 1 (Continued)

\begin{tabular}{|c|c|c|c|c|c|c|c|c|}
\hline \multirow[t]{2}{*}{$\mathrm{RT}(\min )$} & \multirow[t]{2}{*}{$\mathrm{KI}^{\mathrm{a}}$} & \multirow[t]{2}{*}{ Compound } & \multirow[t]{2}{*}{ Identity $^{\mathrm{b}}$} & \multicolumn{5}{|c|}{ SPME coating } \\
\hline & & & & PA & CW/DVB & CAR/PDMS & PDMS & DVB/CAR/PDMS \\
\hline 49.500 & 2162 & Nonanoic acid & B & $\mathrm{x}$ & $\mathrm{X}$ & $\mathrm{X}$ & & $\mathrm{x}$ \\
\hline 53.494 & 2225 & DDMP $^{g}$ & A, B & $\mathrm{x}$ & & $\mathrm{x}$ & $\mathrm{x}$ & $\mathrm{x}$ \\
\hline 55.814 & 2251 & 2,3,4-Trimethyl-hexane & $\mathrm{A}, \mathrm{B}$ & & & & $\mathrm{x}$ & $\mathrm{x}$ \\
\hline 58.057 & 2275 & 2-Acetylbenzoic acid & $\mathrm{B}$ & & $\mathrm{x}$ & & & \\
\hline 61.825 & 2345 & 4-Hydroxy-benzenmethanol & $\mathrm{B}$ & & & & $\mathrm{x}$ & \\
\hline 63.381 & 2395 & 5-Hydroxymethylfurfural & $\mathrm{B}$ & $\mathrm{x}$ & & $\mathrm{x}$ & $\mathrm{x}$ & $\mathrm{x}$ \\
\hline 64.113 & 2418 & 2,6-Dimethoxy-4-(2-propenyl)-phenol & $\mathrm{B}$ & & $\mathrm{X}$ & & & \\
\hline 65.352 & 2457 & Dihydro-4-hydroxy-2(3H)-furanone & $\mathrm{A}, \mathrm{B}$ & & & & & $\mathrm{x}$ \\
\hline $\begin{array}{l}\text { Total compounds } \\
\text { identified by } \\
\text { fibre }\end{array}$ & & & & 32 & 30 & 35 & 17 & 50 \\
\hline
\end{tabular}

${ }^{a}$ Experimentally determined Kovàts indices on the BP-20 column, relative to $\mathrm{C}_{8}-\mathrm{C}_{20}$ hydrocarbons.

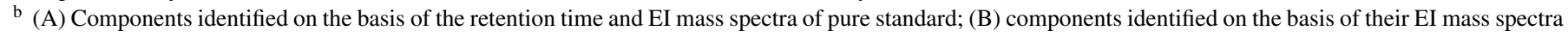
only.

c 1,7,7-Trimethyl-bicyclo[2.2.1] hepten-2-ene.

d 2,2-Dimethyl-2-phenylethyl ester propanoic acid.

e 1-(2,6,6-Trimethyl-1,3-cyclohexadien-1-yl)-2-buten-1-one.

f 4,6-Di(1,1-dimethylethyl)-2-methylphenol.

g 2,3-Dihydro-3,5-dihydroxy-6-methyl-4H-pyran-4one.

Each type of honey showed a typical composition. H1 honey (Fig. 3) is characterized by a high amount of ethanol, furfural, nonanal, 1,3-dihydroxy-2-propanone, trans-linalool oxide, benzaldehyde, hotrienol, and nonanol. Some identified compounds are specific of this sample. Therefore, heptanal, ethyl heptanoate, $\alpha$ - and $\beta$-cububene, (Z)-heptene, $\alpha$-propenyl-2-benzenemethanol, pulegone, acetophenone, 3-carene, D-germacrene and 2,3,4-trimethylhexane, were identified only in this honey sample. This sample is also characterized by the lowest level of 5-hydroxymethylfurfural.

$\mathrm{H} 2$ (Fig. 3) is characterized by a high amount of hotrienol. This compound was identified in each honey analysed but at lower levels. Also 5-hydroxymethylfurfural, benzeneacetaldehyde, furfural and trans-linalool oxide, are present in significantly high amounts, when compared with the H1,
$\mathrm{H} 3$ and $\mathrm{H} 4$ honey samples. 1,3,8-p-menthatriene, 1-ethyl-2methylcyclopropane, cycloheptane, and $\beta$-phenylethanol, are present only in $\mathrm{H} 2$ honey type.

In H3 honey were identified 60 volatile compounds. As shows Fig. 3, the most intense peaks correspond to $o$-methoxyacetophenone, benzeneacetaldehyde, hotrienol, furfural, ethyl dodecanoate and 2-ethyl hexanoic acid. $o$-methoxyacetophenone and 2-ethyl hexanoic acid can be used to differentiate these honey type from $\mathrm{H} 1, \mathrm{H} 2$ and $\mathrm{H} 4$ samples, since were detected, at high levels, only in this sample. 5-Hydroxymethylfurfural, 1,3-dihydroxy-2-propanone, translinalool oxide, furfural, hotrienol and benzeneacetaldehyde, are the dominating components found in the $\mathrm{H} 4$ sample. Fortyeight compounds were positively identified in this honey with the experimental conditions used. 3-Methyl-1-butanol, $(E)$-2hexen-1-ol, 3-methyl-1-pentanol, 5-acetoxymethylfurfural and

Table 2

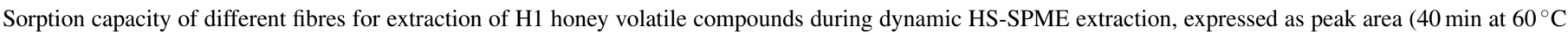
with salt saturation)

\begin{tabular}{|c|c|c|c|c|c|}
\hline \multirow[t]{2}{*}{ Class of compounds } & \multicolumn{5}{|l|}{ SPME fibre } \\
\hline & PA & CW/DVB & DVB/CAR/PMS & PDMS & CAR/PDMS \\
\hline Higher alcohols & $1.10 \times 10^{8}$ & $1.12 \times 10^{8}$ & $8.07 \times 10^{7}$ & $5.34 \times 10^{7}$ & $1.00 \times 10^{8}$ \\
\hline Fatty acids & $7.78 \times 10^{6}$ & $3.53 \times 10^{6}$ & $1.23 \times 10^{6}$ & $8.04 \times 10^{5}$ & $5.71 \times 10^{5}$ \\
\hline Ethyl esters & - & - & $2.85 \times 10^{6}$ & - & $6.70 \times 10^{5}$ \\
\hline $\mathrm{NT}^{\mathrm{a}}$ & $2.16 \times 10^{6}$ & $6.08 \times 10^{6}$ & $8.95 \times 10^{6}$ & $1.99 \times 10^{6}$ & $8.34 \times 10^{6}$ \\
\hline Sesquiterpenoids & - & $5.21 \times 10^{5}$ & $1.63 \times 10^{6}$ & - & - \\
\hline Furanic compounds & $1.04 \times 10^{8}$ & $1.43 \times 10^{7}$ & $7.16 \times 10^{6}$ & $1.33 \times 10^{7}$ & $3.60 \times 10^{7}$ \\
\hline Carbonyl compounds & $4.71 \times 10^{7}$ & $3.05 \times 10^{6}$ & $1.19 \times 10^{7}$ & $5.75 \times 10^{5}$ & $1.91 \times 10^{7}$ \\
\hline HSHAr $^{\mathrm{b}}$ & $2.98 \times 10^{6}$ & $7.57 \times 10^{6}$ & $1.38 \times 10^{7}$ & $5.06 \times 10^{6}$ & $5.67 \times 10^{6}$ \\
\hline Miscellaneous & $1.95 \times 10^{6}$ & - & $5.64 \times 10^{5}$ & - & $3.10 \times 10^{5}$ \\
\hline Sum & $2.04 \times 10^{8}$ & $1.63 \times 10^{8}$ & $2.84 \times 10^{8}$ & $9.09 \times 10^{7}$ & $1.71 \times 10^{8}$ \\
\hline$\%$ R.S.D. $(n=4)$ on sum & 4.66 & 4.89 & 2.81 & 1.67 & 11.63 \\
\hline
\end{tabular}

${ }^{\text {a }} \mathrm{C}_{13}$-norisoprenoids and monoterpenes.

b Aliphatic and aromatic hydrocarbons. 
Table 3

Volatile compounds identified in different types of Portuguese honeys after dynamic headspace solid-phase microextraction using DVB/CAR/PDMS coating (extraction temperature: $60^{\circ} \mathrm{C}$; extraction time: $40 \mathrm{~min}$ )

\begin{tabular}{|c|c|c|c|c|c|c|c|c|c|c|}
\hline \multirow[t]{2}{*}{ RT (min) } & \multirow[t]{2}{*}{$\mathrm{KI}^{\mathrm{a}}$} & \multirow[t]{2}{*}{ Compound } & \multicolumn{4}{|c|}{ RPA (\%) } & \multicolumn{4}{|c|}{$\mathrm{RPC}(\%)$} \\
\hline & & & H1 & $\mathrm{H} 2$ & $\mathrm{H} 3$ & $\mathrm{H} 4$ & $\mathrm{H} 1$ & $\mathrm{H} 2$ & $\mathrm{H} 3$ & $\mathrm{H} 4$ \\
\hline 2.575 & 929 & Ethanol & 56.16 & 41.86 & 44.27 & 29.30 & 51 & 69 & 100 & 98 \\
\hline 3.228 & 992 & Tricloromethane & - & - & 1.25 & - & - & - & 100 & - \\
\hline 3.614 & 1023 & Toluene & 3.99 & 2.95 & 2.32 & 1.61 & 48 & 72 & 80 & 100 \\
\hline 5.941 & 1162 & 2,6-Dimethyl-4-heptanone & - & - & - & 0.09 & - & - & - & 100 \\
\hline 6.295 & 1178 & Heptanal & 0.60 & - & - & - & 100 & - & - & - \\
\hline 7.105 & 1212 & 3-Methyl-1-butanol & - & - & - & 0.16 & - & - & - & 100 \\
\hline 8.187 & 1252 & 3-Octanone & - & 0.35 & - & 0.10 & - & 100 & - & 80 \\
\hline 8.252 & 1254 & Styrene & - & - & 0.16 & - & - & - & 100 & - \\
\hline 8.259 & 1254 & 1,3-Butanediol & 0.25 & - & - & - & 100 & - & - & - \\
\hline 8.481 & 1261 & 1-Methyl-2-(1-methylethyl)-benzene & 0.19 & 0.14 & 0.13 & 0.12 & 35 & 41 & 58 & 100 \\
\hline 9.377 & 1289 & 1-Methoxy-2-methyl-propane & - & - & - & 0.26 & - & - & - & 100 \\
\hline 9.942 & 1307 & 1-Hydroxy-2-propane & 0.95 & 0.54 & - & 0.22 & 100 & 55 & - & 96 \\
\hline 10.387 & 1322 & 2-Heptanol & - & - & - & 0.14 & - & - & - & 100 \\
\hline 12.524 & 1385 & Methyl ester octanoic acid & - & - & 0.49 & 0.15 & - & - & 100 & 57 \\
\hline 12.668 & 1389 & Nonanal & 6.94 & - & - & - & 100 & - & - & - \\
\hline 12.629 & 1388 & (E)-2-Hexen-1-ol & - & - & - & 0.36 & - & - & - & 100 \\
\hline 12.796 & 1392 & (E)-2-Nonen-1-ol & 0.93 & 1.25 & 1.55 & - & 17 & 53 & 100 & - \\
\hline 14.100 & 1431 & 1-Methyl-4-(1-methylethenyl)-benzene & - & 0.67 & 1.05 & 0.36 & - & 43 & 100 & 64 \\
\hline 14.13 & 1432 & Heptanoic acid ethyl ester & 0.20 & - & - & - & 100 & - & - & - \\
\hline 14.267 & 1436 & 1,4-Dichloro-benzene & 1.05 & - & - & - & 100 & - & - & - \\
\hline 14.401 & 1439 & Trans-linalool oxide & 4.99 & 7.83 & 4.92 & 3.90 & 30 & 73 & 69 & 100 \\
\hline 14.469 & 1441 & 1,3,8-p-Menthatriene & - & 0.39 & - & - & - & 100 & - & - \\
\hline 15.025 & 1457 & Acetic acid & 1.12 & 2.11 & 0.90 & 0.78 & 35 & 99 & 66 & 100 \\
\hline 15.368 & 1466 & Furfural & 8.09 & 11.31 & 6.10 & 3.62 & 32 & 100 & 82 & 88 \\
\hline 15.767 & 1477 & $\alpha$-Cubebene & 1.67 & - & - & - & 100 & - & - & - \\
\hline 16.13 & 1486 & Methyl ester nonanoic acid & - & - & 0.55 & 0.13 & - & - & 100 & 43 \\
\hline 16.241 & 1489 & 2-Ethyl-1-hexanol & - & - & 0.29 & - & - & - & 100 & - \\
\hline 16.358 & 1492 & Decanal & - & 0.86 & 0.31 & 0.14 & - & 100 & 53 & 45 \\
\hline 16.535 & 1496 & Benzofuran & - & - & 0.85 & - & - & - & 100 & - \\
\hline 16.578 & 1497 & Hexadecane & 0.34 & - & - & 0.19 & 29 & - & - & 100 \\
\hline 16.764 & 1502 & 1-(2-Furanyl)-ethanone & 0.20 & 0.92 & 0.60 & 0.27 & 14 & 100 & 98 & 80 \\
\hline 16.917 & 1505 & 1-(1,4-Dimethyl-3-cyclohexen-1-yl)-ethanone & - & - & 0.41 & 0.18 & - & - & 100 & 79 \\
\hline 17.009 & 1508 & 1,7,7-Trimethyl-bicyclo[2.2.1]hepten-2-ene & 0.35 & - & - & - & 100 & - & - & - \\
\hline 17.3 & 1515 & Benzaldehyde & 4.60 & 2.80 & 0.80 & - & 73 & 100 & 44 & - \\
\hline 17.47 & 1518 & 2-Nonanol & - & - & 0.76 & - & - & - & 100 & - \\
\hline 18.009 & 1531 & Ethyl ester octanoic acid & - & - & 0.34 & - & - & - & 100 & - \\
\hline 18.849 & 1549 & $(S)$-Linalool & 1.46 & 0.78 & 1.16 & 0.56 & 51 & 44 & 100 & 88 \\
\hline 19.189 & 1557 & Cis-1-ethyl-2-methyl-cyclopropane & - & 0.37 & - & - & - & 100 & - & - \\
\hline 19.192 & 1557 & $(S)-(+)-3-M e t h y l-1-$ pentanol & - & - & - & 0.17 & - & - & - & 100 \\
\hline 19.801 & 1569 & 5-Methylfurfural & 0.32 & 0.5 & 0.32 & - & 28 & 99 & 100 & - \\
\hline 20.774 & 1589 & 2-Methyl benzofuran & - & - & 0.86 & - & - & - & 100 & - \\
\hline 21.343 & 1600 & $\alpha$-4-Dimethyl-3-cyclohexene-1-acetaldehyde & 0.10 & 0.84 & - & 0.17 & 21 & 100 & - & 55 \\
\hline 21.840 & 1611 & Hotrienol & 3.79 & 30.33 & 7.20 & 4.98 & 8 & 100 & 36 & 45 \\
\hline 22.144 & 1617 & Dihydro-cis- $\alpha$-copaene- 8 -ol & 0.02 & - & - & - & 100 & - & - & - \\
\hline 22.562 & 1626 & 1-Ethenyl-4-methoxybenzene & - & - & 0.72 & - & - & - & 100 & - \\
\hline 22.589 & 1626 & Pulegone & 0.14 & - & - & - & 100 & - & - & - \\
\hline 22.893 & 1633 & Phenylacetaldehyde & 0.50 & 12.44 & 7.92 & 3.69 & 2 & 100 & 89 & 82 \\
\hline 23.122 & 1637 & Acetophenone & 1.24 & - & - & - & 100 & - & - & - \\
\hline 23.475 & 1644 & 3-Carene & 0.29 & - & - & - & 100 & - & - & - \\
\hline 23.661 & 1648 & 2-Hydroxy-3,5,5-trimethyl-cyclohex-2-enone & - & 0.87 & - & 0.50 & - & 68 & - & 100 \\
\hline 24.252 & 1660 & 1-Nonanol & 4.04 & 1.18 & 1.00 & 0.66 & 100 & 60 & 83 & 99 \\
\hline 24.436 & 1663 & 2-Furanmethanol & 1.52 & 1.51 & - & 1.32 & 27 & 36 & - & 100 \\
\hline 25.105 & 1676 & 2,6,6-Trimethyl-2-cyclohexene-1,4-dione & - & 0.38 & 0.55 & 0.27 & - & 60 & 100 & 89 \\
\hline 25.472 & 1683 & D-Germacrene & 0.60 & - & - & - & 100 & - & - & - \\
\hline 25.681 & 1687 & 1-Methyl-4-(1-methylethylidene)-cyclohexene & - & - & 0.20 & - & - & - & 100 & - \\
\hline 25.703 & 1687 & 2,6-Dimethyl-5,7-octadien-2-ol & - & 0.14 & - & 0.11 & - & 10 & 100 & 16 \\
\hline 26.272 & 1697 & Eicosane & - & 1.22 & 1.26 & - & - & 100 & 95 & - \\
\hline 26.312 & 1698 & Heptadecane & 2.40 & - & - & 0.64 & 84 & - & - & 100 \\
\hline 27.011 & 1712 & 8-Heptadecane & - & - & 0.29 & - & - & - & 100 & - \\
\hline 27.090 & 1714 & Naphthalene & 4.45 & - & 0.14 & - & 100 & - & 11 & - \\
\hline 27.318 & 1719 & 2-Heptadecanol & - & - & 0.78 & - & - & - & 100 & - \\
\hline
\end{tabular}


Table 3 (Continued)

\begin{tabular}{|c|c|c|c|c|c|c|c|c|c|c|}
\hline \multirow[t]{2}{*}{ RT (min) } & \multirow[t]{2}{*}{$\mathrm{KI}^{\mathrm{a}}$} & \multirow[t]{2}{*}{ Compound } & \multicolumn{4}{|l|}{ RPA $(\%)$} & \multicolumn{4}{|c|}{$\mathrm{RPC}(\%)$} \\
\hline & & & $\mathrm{H} 1$ & $\mathrm{H} 2$ & $\mathrm{H} 3$ & $\mathrm{H} 4$ & $\mathrm{H} 1$ & $\mathrm{H} 2$ & $\mathrm{H} 3$ & $\mathrm{H} 4$ \\
\hline 27.328 & 1719 & 2-Tetradecanol & - & 0.26 & - & - & - & 100 & - & - \\
\hline 27.357 & 1720 & 1,2-Dihydro-3,6,8-trimethyl-naphthalene & - & 0.46 & - & - & - & 100 & - & - \\
\hline 28.038 & 1733 & $\beta$-Cubebene & 0.35 & - & - & - & 100 & - & - & - \\
\hline 29.172 & 1756 & 2-Hydroxy methyl ester benzoic acid & - & 2.02 & - & 0.36 & - & 100 & - & 48 \\
\hline 29.198 & 1756 & Methyl ester 2-hidroxy-benzoic acid & 0.52 & - & - & - & 100 & - & - & - \\
\hline 29.368 & 1759 & Cis- $\alpha$-bisabolene & 0.25 & - & - & - & 100 & - & - & - \\
\hline 29.446 & 1761 & Cycloheptane & - & 0.56 & - & - & - & 100 & - & - \\
\hline 29.453 & 1761 & 2-Methyl-cyclopentanone & - & - & - & 0.33 & - & - & - & 100 \\
\hline 29.734 & 1766 & $(Z)$-Heptene & 0.96 & - & - & - & 100 & - & - & - \\
\hline 30.400 & 1779 & 4-Hydroxy-acetophenone & - & - & 0.25 & - & - & - & 100 & - \\
\hline 31.182 & 1793 & Methyl ester dodecanoic acid & - & - & 0.81 & - & - & - & 100 & - \\
\hline 31.587 & 1800 & 2-Phenylethyl ester propanoic acid & - & - & 0.33 & 0.30 & - & - & 61 & 100 \\
\hline 31.591 & 1801 & 2,2-Dimethyl-2-phenylethyl ester propanoic acid & 4.99 & - & - & - & 100 & - & - & - \\
\hline 31.819 & 1805 & $(S)$ - $\alpha$-Methyl-benzenemethanol & 0.57 & - & 0.42 & - & 55 & - & 100 & - \\
\hline 33.395 & 1837 & Ethyl ester dodecanoic acid & - & 1.38 & 6.80 & - & - & 15 & 100 & - \\
\hline 33.424 & 1838 & Ethyl ester decanoic acid & - & - & - & 0.22 & - & - & - & 100 \\
\hline 33.594 & 1841 & $\alpha$-4-Trimethyl-benzenemethanol & - & - & - & 0.11 & - & - & - & 100 \\
\hline 33.774 & 1845 & (E)-6,10-Dimethyl-5,9-undecadien-2-one & 2.15 & - & 0.96 & - & 91 & - & 100 & - \\
\hline 34.336 & 1856 & 3-Methylbuthyl ester pentadecanoic acid & - & - & 0.24 & - & - & - & 100 & - \\
\hline 34.901 & 1866 & Phenol & - & - & 0.64 & - & - & - & 100 & - \\
\hline 35.010 & 1869 & $\alpha$-2-Propenyl-benzenmethanol & 0.78 & - & - & - & 100 & - & - & - \\
\hline 36.565 & 1897 & $\beta$-Phenylethanol & - & 1.84 & - & - & - & 100 & - & - \\
\hline 36.628 & 1898 & Nonadecane & 2.53 & - & 1.90 & 0.89 & 54 & - & 100 & 85 \\
\hline 36.830 & 1902 & $\alpha$-Ionol & - & - & 0.56 & - & - & - & 100 & - \\
\hline 36.918 & 1904 & 4,6-Di-(1,1-dimethylethyl)-2-methyl phenol & 1.80 & - & - & - & 100 & - & - & - \\
\hline 37.052 & 1907 & Benzyl nitrile & - & - & 0.26 & 0.16 & - & - & 91 & 100 \\
\hline 38.602 & 1939 & 2,3,4,5-Tetramethyl-1,4-hexadiene & - & - & - & 0.97 & - & - & - & 100 \\
\hline 38.951 & 1946 & 2-Ethyl hexanoic acid & - & - & 6.08 & - & - & - & 100 & - \\
\hline 40.203 & 1971 & $o$-Methoxyacetophenone & - & - & 19.25 & - & - & - & 100 & - \\
\hline 40.664 & 1979 & $\mathrm{MFPOE}^{\mathrm{b}}$ & - & - & - & 0.29 & - & - & - & 100 \\
\hline 40.906 & 1984 & Furyl hydroxymethyl ketone & - & - & - & 0.41 & - & - & - & 100 \\
\hline 41.71 & 1999 & Methyl tetradecanoate & - & - & 0.48 & - & - & - & 100 & - \\
\hline 43.727 & 2042 & Ethyl ester tetradecanoic acid & - & - & 0.55 & - & - & - & 100 & - \\
\hline 44.358 & 2055 & Octanoic acid & - & 0.81 & 1.61 & 0.68 & - & 46 & 100 & 78 \\
\hline 45.355 & 2075 & 1,3-Dihydroxy-2-propanone & 6.20 & 6.97 & 5.61 & 6.90 & 18 & 53 & 45 & 100 \\
\hline 46.548 & 2098 & 10-Methyleicosane & 0.75 & - & - & - & 100 & - & - & - \\
\hline 49.862 & 2170 & Cyclododecane & - & - & 0.42 & - & - & - & 100 & - \\
\hline 50.189 & 2176 & 5-Acetoxymethylfurfural & - & - & - & 0.29 & - & - & - & 100 \\
\hline 50.679 & 2186 & Nonanoic acid & 0.70 & 0.75 & 1.01 & 0.34 & 26 & 57 & 100 & 63 \\
\hline 51.673 & 2204 & 15-Methyl ester hexadecanoic acid & - & - & 0.40 & - & - & - & 100 & - \\
\hline 53.461 & 2225 & Ethyl ester hexadecanoic acid & - & - & 0.72 & - & - & - & 100 & - \\
\hline 53.824 & 2229 & $\mathrm{DDMP}^{\mathrm{c}}$ & 1.61 & 2.23 & 0.70 & 1.61 & 24 & 57 & 25 & 100 \\
\hline 54.464 & 2236 & Ethyl ester $E$-11 hexadecanoic acid & - & - & 1.02 & - & - & - & 100 & - \\
\hline 54.732 & 2239 & 2,3-Dimethoxy-naphthalene & - & - & 1.67 & - & - & - & 100 & - \\
\hline 55.814 & 2251 & 2,3,4-Trimethyl-hexane & 6.06 & - & - & - & 100 & - & - & - \\
\hline 59.217 & 2287 & 3,5-Dimethoxy methyl ester benzoic acid & - & - & 0.82 & - & - & - & 100 & - \\
\hline 63.074 & 2345 & Dodecanoic acid & - & - & 1.12 & - & - & - & 100 & - \\
\hline 63.381 & 2395 & 5-Hydroxymethylfurfural & 0.31 & 14.71 & 4.86 & 10.93 & 1 & 59 & 29 & 100 \\
\hline 65.352 & 2457 & Dihydro-4-hydroxy-2-(3H)-furanone & 0.33 & - & - & 0.37 & 21 & - & - & 100 \\
\hline $\begin{array}{l}\text { Total compounds } \\
\text { identified by } \\
\text { honey }\end{array}$ & & & & & & & 50 & 37 & 60 & 48 \\
\hline Sum of total area & $2.8 \times 10^{8}$ & $4.3 \times 10^{8}$ & $5.2 \times 10^{8}$ & $5.12 \times 10^{8}$ & & & & & & \\
\hline$\%$ R.S.D. $(n=4)$ & 2.81 & 1.95 & 7.35 & 7.30 & & & & & & \\
\hline
\end{tabular}

${ }^{a}$ Experimentally determined Kovàts indices on the BP-20 column, relative to $\mathrm{C}_{8}-\mathrm{C}_{20}$ hydrocarbons.

b 1-[3-[2-Methyl-2-[5-methyl-2-furanyl]propyl]oxiranyl]-ethanone.

c 2,3-Dihydro-3,5-dihydroxy-6-methyl-4H-pyran-4-one. 

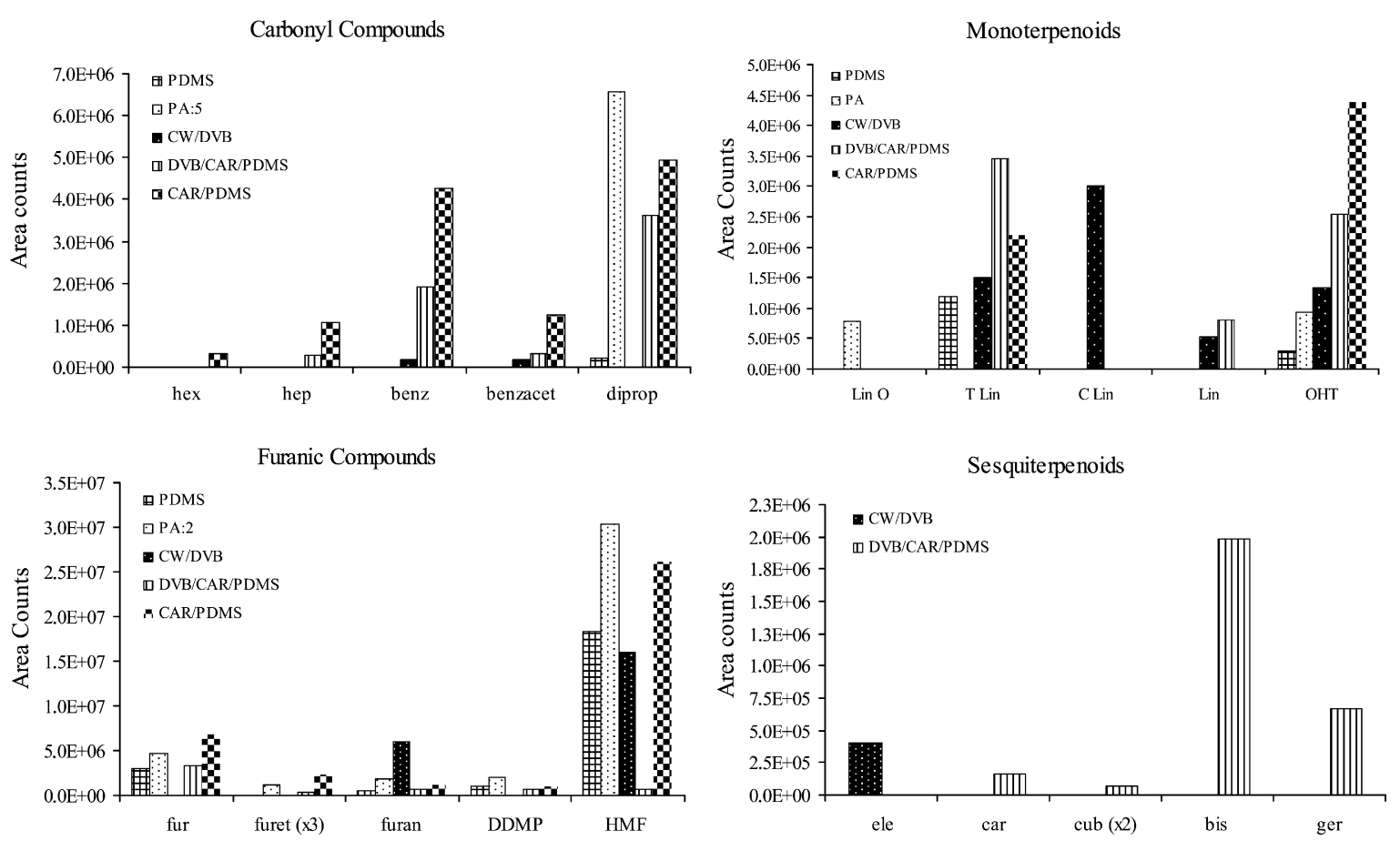

Fig. 2. Comparison of the performance of different SPME coatings on the carbonyl compounds, monoterpenoids, furanic compounds and sesquiterpenoids extraction (hex: hexane; hep: heptane; benz: benzaldehyde; benzacet: benzeneacetaldehyde; diprop: 1,3-hydroxy-2-propanone; Lin O: linalool oxide; T Lin: trans-linalool oxide; C Lin: cis-linalool oxide; Lin: linalool; OHT: hotrienol; fur: furfural; furet: 1-(2-furanyl)-ethanone; furan: furanmethanol; DDMP: 2,3-dihydro-3,5-dihydroxy-6methyl-4H-pyran-4-one; HMF: 5-hydroxymethylfurfural; ele: $\beta$-elemene; car: 3 -carene; cub: $\beta$-cubebene; bis: $\alpha$-bisabolene; ger: D-germacrene).

2-methylcyclopentanone, has been detected only in this honey sample. Fig. 4 presents the distribution of compounds classes by honey sample.

The presence of several honey constituents found in this study have been previously reported. The presence of hotrienol in the Eucryphia lucida honey [38]. We have also found, for instance aromatic aldehydes such as benzaldehyde and benzeneacetaldehyde, which have been reported as common components of various unifloral honey [39].

\subsection{Multivariate analysis}

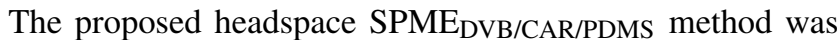
applied to four different commercial honeys. Evidently, the different concentrations of the volatile constituents determined in these samples allow their differentiation. Although the volatile compounds studied showed important data for the characterization of honey samples, the differentiation is quite difficult to establish from the direct observation of Table 3. Multivariate techniques of data analysis represent a powerful statistical tool to explain this differentiation. The total peak area of each chemical group, higher alcohols (HA), fatty acids (FAc), ethyl esters (EEs), $\quad \mathrm{C}_{13}$-norisoprenoids/monoterpenols/sesquiterpenoids (NTS1), furanic compounds (FC), carbonyl compounds (CaC) and aliphatic/aromatic hydrocarbons (HSHAr), were used as variable vectors for multivariate analysis in order to obtain more detailed information. When PCA was applied to the total peak area different chemical classes, three factors were extracted and $98.3 \%$ of the total variance was explained (Table 4). As can be seen in Fig. 5a, a clear separation can be observed. Considering the factor loadings of the variables (Table 5), the most influential variables (chemical groups) to the first component (PC1, 50.1\%), are carbonyl compounds, ethyl esters and fatty acids, while NTS1, HSHAr $(25.9 \%)$ and furan derivatives (22.3\%), are the variables that most contribute to the PC2 and PC3, respectively. Fig. 5a shows the scores scatter plot of the first two principal components $(50.1 \%$ of the total variability) that represents the

Table 4

Percentage of variance and percentage of cumulative variance explained by the three first principal components

\begin{tabular}{|c|c|c|c|c|c|c|}
\hline \multirow[t]{2}{*}{ Component } & \multicolumn{6}{|c|}{ Total variance explained } \\
\hline & Total & $\%$ of variance & Cumulative $\%$ & Total & $\%$ of variance & Cumulative \% \\
\hline 1 & 3.771 & 53.877 & 53.877 & 3.509 & 50.124 & 50.124 \\
\hline 2 & 2.449 & 34.988 & 88.864 & 1.814 & 25.917 & 76.041 \\
\hline 3 & 0.664 & 9.491 & 98.355 & 1.562 & 22.314 & 98.355 \\
\hline
\end{tabular}

Extraction method: principal component analysis. 


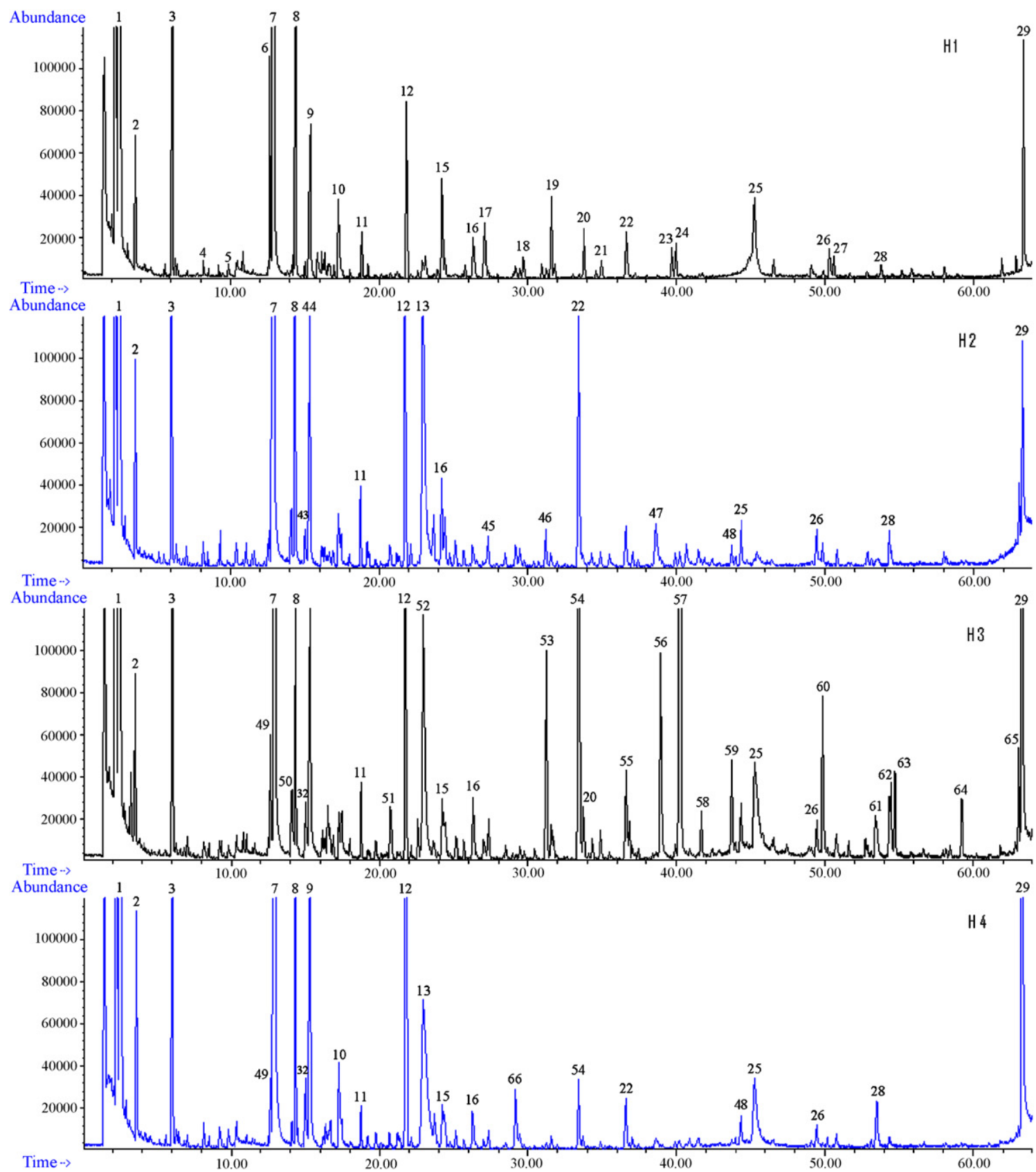

Fig. 3. Comparison of GC-qMS profiles of HS-SPME $E_{\mathrm{DVB} / \mathrm{CAR} / \mathrm{PDMS}} \mathrm{H} 1-\mathrm{H} 4$ honey extracts obtained at $60^{\circ} \mathrm{C}$ during $40 \mathrm{~min}$. Peak identification: (1) ethanol; (2) toluene; (3) 4-methyl-2-pentanol (IS); (4) 1,3-butanediol; (5) 1-hydroxy-2-propanone; (6) nonanal; (7) 3-octanol (IS); (8) trans-linalool oxide; (9) furfural; (10) benzaldehyde; (11) linalool; (12) hotrienol; (13) benzeneacetaldehyde; (14) acetophenone; (15) 1-nonanol; (16) eicosane; (17) naphthalene; (18) 3-ethyl-2pentene; (19) 2-methyl-2-phenylethyl ester propanoic acid; (20) E-6,10-dimethyl-5,9-undecadien-2-one; (21) $\alpha$-2-propenyl-benzenemethanol; (22) heptadecane; (23) 2-ethyl-hexanoic acid; (24) 1-ethyl-2-hepthyl-cyclopropane; (25) 1,3-dihydroxy-2-propanone; (26) nonanoic acid; (27) $N$-(4-hydroxyphenyl)acetamide; (28) 2,3-dihydro-3,5-dihydroxy-6-methyl-4H-pyran-4-one; (29) 5-hydroxymethylfurfural; (31) $\alpha$-ionol (32) acid acetic; (33)-(42) (compounds from 33 to 42 were not detected with this fibre); (43) 1-methyl-4-(1-methylethyl)-benzene; (44) cis linalool oxide; (45) 2-undecanol; (46) 2-methyl-cyclopentanone; (47) 2,3,4,5-tetramethyl1,4-hexadiene; (48) octanoic acid; (49) 2-nonen-1-ol; (50) ethyl ester octanoic acid; (51) methyl ester decanoic acid; (52) ethyl ester decanoic acid; (53) methyl ester dodecanoic acid; (54) ethyl ester dodecanoic acid; (55) phenol; (56) 2-ethyl hexanoic acid; (57) o-methoxyacetophenone; (58) methyl tetradecanoate; (59) ethyl ester tetradecanoic acid; (60) cyclododecane; (61) ethyl ester hexadecanoic acid; (62) ethyl ester hexadecanoic acid E11; (63) 5,7,8-trimethyl coumarin; (64) 3,5-dimethoxy-methyl ester benzoic acid; (65) dodecanoic acid; (66) 2-hydroxy methyl ester benzoic acid.

distinction among the honey samples. Fig. 5b represents the corresponding loadings plot that established the relative importance of each chemical group. $\mathrm{H} 1$ and $\mathrm{H} 2$ honeys (third quadrant) are characterized by the carbonyl compounds $(\mathrm{CaC})$, ethyl esters (EEs) and in lower extent, by fatty acids
(FAc). The $\mathrm{H} 3$ honey is related to the positive PC1 side. Higher alcohols, is the variable which characterize them. H4 honey represented in the second quadrant being characterized by carbonyl compounds $(\mathrm{CaC})$ and fatty acids (FAc) (Fig. 5b). 


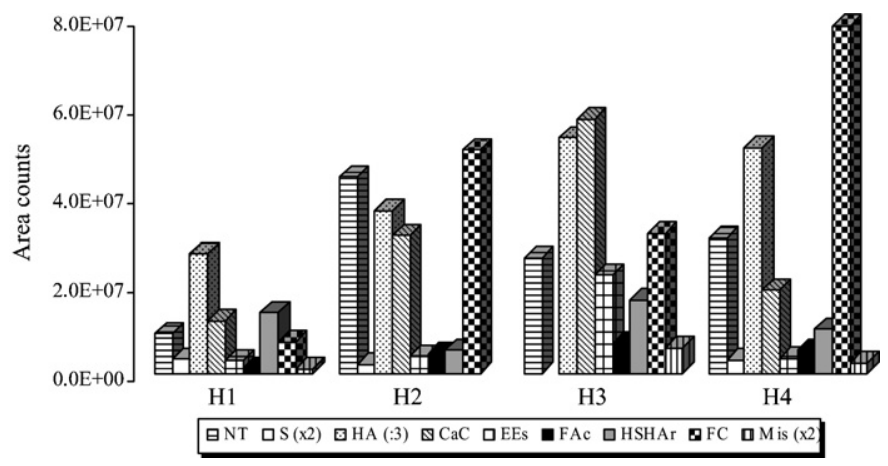

Fig. 4. Distribution of compounds classes by honey samples (NT: $\mathrm{C}_{13}$ norisoprenoids and monoterpenoids; S: sesquiterpenoids; HA: higher alcohols; CaC: carbonyl compounds; EEs: ethyl esters; FAc: fatty acids; HSHAr: aliphatic and aromatic hydrocarbons; FC: furanic compounds; Mis: miscellaneous).

Table 5

Loadings of volatiles in the first three principal components

\begin{tabular}{lccc}
\hline & \multicolumn{2}{l}{ Rotated component matrix $^{\mathrm{a}}$} \\
\cline { 2 - 4 } & Component 1 & Component 2 & Component 3 \\
\hline CC & 0.994 & 0.081 & -0.019 \\
EE & 0.960 & -0.220 & -0.060 \\
FA & 0.783 & 0.208 & 0.579 \\
Alc & 0.781 & -0.169 & 0.556 \\
NTS & 0.186 & 0.938 & 0.284 \\
HSHA & 0.579 & -0.802 & -0.124 \\
F & -0.057 & 0.403 & 0.904 \\
\hline
\end{tabular}

(1) PC1; (2) PC2 and (3) PC3; rotation method: Varimax with Kaiser normalization; CC: carbonyl compounds; EE: ethyl esters; FA: fatty acids; Alc: higher alcohols; NTS: $\mathrm{C}_{13}$-norisoprenoids, monoterpenoids and sesquiterpenoids; HSHA: aliphatic and aromatic hydrocarbons; F: furanic compounds. Extraction method: principal component analysis. Rotation method: Varimax with Kaiser normalization.

${ }^{\text {a }}$ Rotation converged in five iterations.

After PCA, a linear discriminant analysis (LDA) was run, using the above-mentioned variables, in order to obtain suitable classification rules. Fig. 6 shows a projection of the honeys in two-dimensional space, generated by the two first discriminate
Table 6

Prediction abilities for the different honeys, using stepwise discriminant analysis

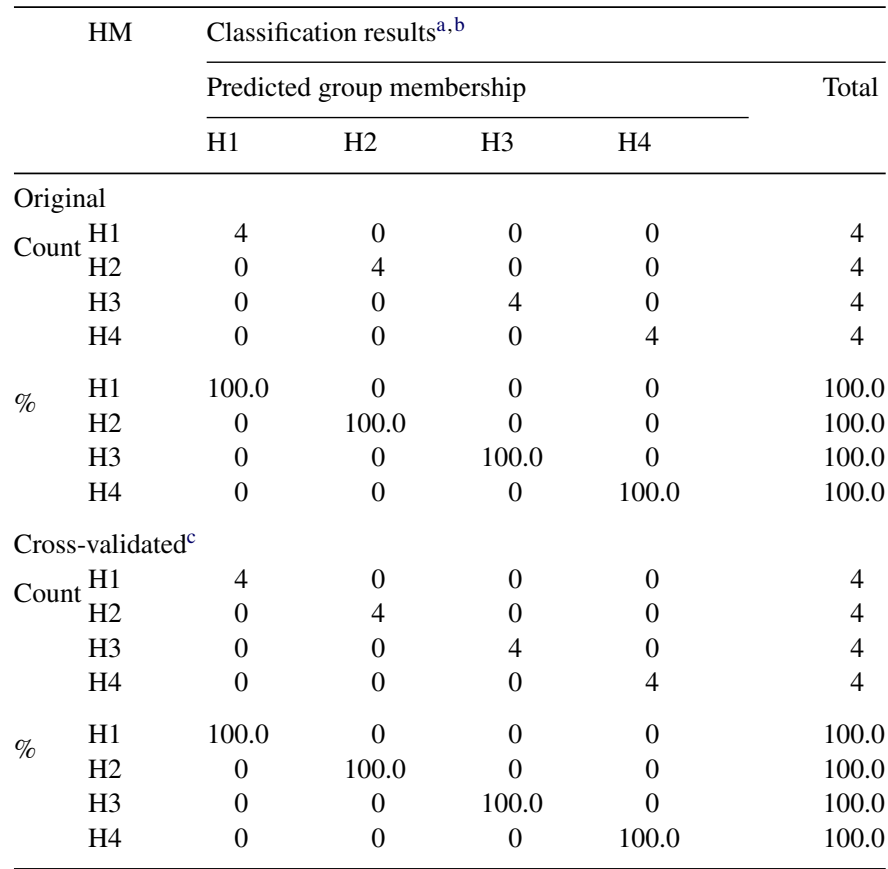

a $1000 \%$ of original grouped cases correctly classified.

b $1000 \%$ of cross-validated grouped cases correctly classified.

${ }^{c}$ Cross-validation is done only for those cases in the analysis. In crossvalidation, each case is classified by the functions derived from all cases other than that case.

functions that explain $97.9 \%$ of the total variance. Four groups representing each honey, $\mathrm{H} 1-\mathrm{H} 4$, were clearly observed. The good agreement achieved indicates that very acceptable classification functions can be deduced. The leave one out method was used as cross-validation procedure to evaluate the classification performance (Table 6).

From the results it can be concluded that headspace SPME coupled to GC-qMS and chemometrics is a very appropriate sampling technique to distinguish the different Portuguese honeys studied based on their volatile profile.
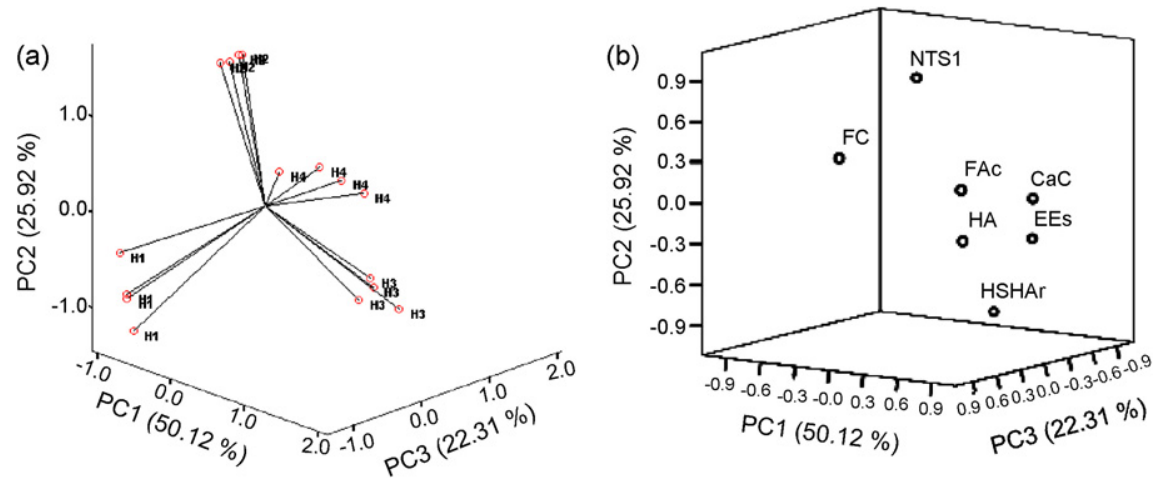

Fig. 5. PC1 and PC2 scatter plot of the main sources of variability between honey samples (H1-H4). (a) Distinction between the samples (scores); (b) relation between the chemical classes (loadings); Variables identification: CaC: carbonyl compounds; EEs: ethyl esters; FAc: fatty acids; HA: higher alcohols; NTS1: $\mathrm{C}_{13}$-norisoprenoids/monoterpenes/sesquiterpenoids; HSHAr: aliphatic and aromatic hydrocarbons; FC: furanic compounds. 


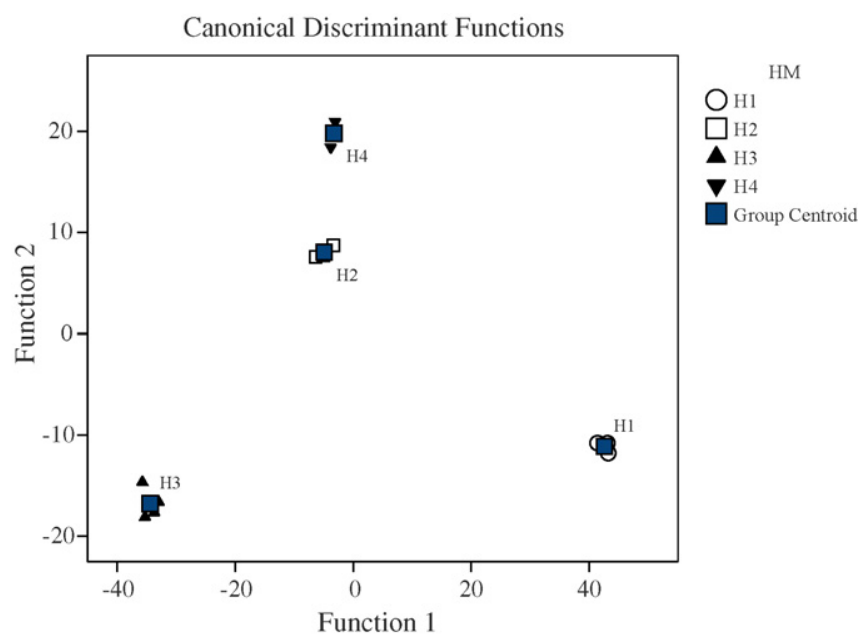

Fig. 6. Differentiation between H1-H4 honeys by applying LDA.

\section{Conclusions}

Headspace solid-phase microextraction sampling followed by $\mathrm{GC}-\mathrm{qMS}$ analysis provides an appropriate and selective way to characterize the volatile compounds in honey. Is a simple procedure of extraction with a great capacity of concentration and combines extraction to a rapid, sensitive and solvent-free method suitable for determination of volatile and semivolatile compounds. The chromatographic profiles obtained after extraction with PDMS, PA, CAR/PDMS, CW/DVB and DVB/CAR/PDMS coatings suggest that the later was the most suitable for the SPME analysis of honey volatiles. The more polar fibre, PA, shows no more effective extraction for polar such as higher alcohols, fatty acids, furan derivatives and carbonyl compounds, while DVB/CAR/PDMS favours the extraction of less polar compounds like ethyl esters, $\mathrm{C}_{13}$-norisoprenoids/monoterpenes, sesquiterpenoids and aliphatic and aromatic hydrocarbons. More than 100 volatile compounds, including higher alcohols, ethyl esters and fatty acids, were identified. The higher alcohols, fatty acids and $\mathrm{C}_{13}$-norisoprenoids/monoterpenes constitute important aroma groups compounds which contributes with "fruity", "cheese/fatty" and "flowery" notes to honey sensory properties. Using a chemometric approach (PCA and LDA), the volatile composition in terms of average peak areas, provides a suitable tool to differentiate between the analysed honeys.

\section{References}

[1] L. Cuevas-Glory, J. Pino, L. Santiago, E. Sauri-Duch, Food Chem. 103 (2007) 1032.

[2] M. Al-Mamary, A. Al-Meeri, M. Al-Habori, Nutr. Res. 22 (2002) 1041.
[3] S. Buratti, S. Benedetti, M. Cosio, Talanta 71 (2007) 1387.

[4] E. Alissandrakis, P. Tarantilis, P. Harizanis, M. Moschos, J. Sci. Food Agric. 85 (2005) 91.

[5] B. D'Arcy, G. Rintoul, C. Rowland, A. Blackman, J. Agric. Food Chem. 45 (1997) 1834.

[6] R. Pérez, C. Sánchez-Brunete, R. Calvo, J. Tadeo, J. Agric. Food Chem. 50 (2002) 2633.

[7] F. Bianchi, M. Carreri, M. Musci, Food Chem. 89 (2005) 527.

[8] C. Guyot, V. Scheirman, S. Collin, Food Chem. 64 (1999) 3.

[9] V. Ferreira, N. Ortin, A. Escudero, R. Lopez, J. Cacho, J. Agric. Food Chem. 50 (2002) 4048.

[10] J. Nuñez, H. Bemelmans, Chromatogr. A 294 (1984) 361.

[11] G. Blanch, G. Reglero, M. Herraiz, J. Agric. Food Chem. 43 (1995) 1251.

[12] R. López, M. Aznar, J. Cacho, V. Ferreira, J. Chromatogr. A 966 (2002) 166.

[13] C. Cocito, G. Gaetano, C. Delfini, Food Chem. 52 (1995) 311

[14] H. Lord, J. Pawliszyn, J. Chromatogr. A 885 (2000) 153.

[15] Z. Zhang, J. Pawliszyn, Anal. Chem. 65 (1993) 1843.

[16] E. Baltussen, P. Sandra, F. David, C. Cramers, J. Microcolumn Sep. 11 (1999) 737.

[17] R. Alves, A. Nascimento, J. Nogueira, Anal. Chim. Acta 546 (2005) 11.

[18] E. Coelho, S.M. Rocha, I. Delgadillo, M.A. Coimbra, Anal. Chim. Acta 563 (2006) 204.

[19] S.M. Rocha, P. Coutinho, A. Barros, I. Delgadillo, M.A. Coimbra, J. Chromatogr. A 1114 (2006) 188.

[20] J. Demyttenaere, C. Dagherb, P. Sandra, S. Kallithraka, R. Verhé, N. Kimpe, J. Chromatogr. A 985 (2003) 233.

[21] M. Begala, L. Corda, G. Podda, M. Fedrido, P. Traldi, Rapid Commun. Mass Spectrom. 16 (2002) 1086.

[22] M. Burmeister, C. Drumond, E. Pfiesterer, D. Hysert, J. Am. Soc. Brew. Chem. 50 (1992) 53.

[23] O. Pinho, I. Ferreira, L. Santos, J. Chromatogr. A 1121 (2006) 145.

[24] J. Câmara, J. Marques, R. Perestrelo, F. Rodrigues, L. Oliveira, P. Andrade, M. Caldeira, J. Chromatogr. A 1150 (2007) 198.

[25] J. Demyttenaere, C. Dagherb, P. Sandra, S. Kallithraka, R. Verhé, N. Kimpe, J. Chromatogr. A 985 (2003) 221.

[26] J. Pino, M. Martí, M. Mestres, J. Pérez, O. Busto, J. Guasch, J. Chromatogr. A 954 (2002) 51.

[27] J. Pino, R. Marbot, C. Vázquez, J. Agric. Food Chem. 49 (2001) 5883

[28] J. Pino, R. Marbot, C. Vázquez, J. Agric. Food Chem. 50 (2002) 6023.

[29] M. Lopez, G. Guzmán, A. Dorantes, J. Chromatogr. A 1036 (2004) 87.

[30] A. Gioacchini, M. Menotta, L. Bertini, I. Rossi, S. Zeppa, A. Zambonelli, G. Piccoli, V. Stocchi, Rapid Commun. Mass Spectrom. 19 (2005) 2365.

[31] F. Augusto, A. Valente, E. Tada, S. Rivellino, J. Chromatogr. A 873 (2000) 117.

[32] E. Alissandrakis, P. Tarantilis, P. Harizanis, M. Polissiou, Food Chem. 100 (2007) 396.

[33] M. Baroni, M. Nores, M. Díaz, G. Chiabrando, J. Fassano, C. Costa, D. Wunderlin, J. Agric. Food Chem. 54 (2006) 7235.

[34] A. Soria, I. Martínez-Castro, J. Sanz, J. Sep. Sci. 26 (2003) 793.

[35] I. Jerković, J. Mastelić, Z. Marijanović, Chem. Biodivers. 3 (2006) 1307.

[36] R. Peña, J. Barciela, C. Herrero, S. Garcia-Martín, J. Sep. Sci. 27 (2004) 1540.

[37] J.S. Câmara, M.A. Alves, J.C. Marques, Anal. Chim. Acta 555 (2006) 191.

[38] C.Y. Rowland, A.J. Blackman, B.R. D’Arcy, G.B. Rintoul, J. Agric. Food Chem. 43 (1995) 753.

[39] L. Piasenzotto, L. Gracco, L. Conte, J. Sci. Food Agric. 83 (2003) 1037. 